\title{
Do We Need to Stent Arterial Duct in Hybrid Approach for Hypoplastic Left Heart Syndrome?
}

\author{
Milad El-Segaier, MD, PhD ${ }^{1,2}$, Mohamed Omar Galal, MD, PhD, MBA ${ }^{3,4}$ \\ ${ }^{1}$ Department of Paediatric Cardiology, King Fahad Medical City, KSHC, Riyadh, Saudi Arabia \\ 2 Department of Paediatric Cardiology, Skåne University Hospital, Lund, Sweden \\ ${ }^{3}$ King Faisal Specialist Hospital \& RC, Jeddah, Saudi Arabia \\ ${ }^{4}$ Kinderklinik, Essen University, Essen, Germany
}

\section{Key Words}

Arterial duct patency - Stent implantation - Hypoplastic Left Heart Syndrome $\bullet$ Hybrid approach

Copyright @ 2017 Science International Corp.

To the Editor,

A Newborn with hypoplastic left heart syndrome (HLHS) cannot survive without an open arterial duct and adequate inter-atrial communication. Prostaglandin infusion is usually used to keep the duct patent and balloon atrial septostomy, if needed, will be performed. Those with large inter-atrial communication may survive the first month of life, but the majority of them will gradually deteriorate and eventually die. The assumed change in pathophysiology leading to death is a reduction in pulmonary vascular resistance leading to lung congestion and less systemic perfusion ending with multi-organ failure.

Norwood cascade of surgical palliations for HLHS was first performed in the early 1980s however during the last 20 years the concept of hybrid approach was introduced. This hybrid intervention encompasses balloon atrial septostomy, and surgical banding of pulmonary artery branches combined with transluminal stenting of the arterial duct. The intervention needs to be performed in a special catheterization laboratory by both cardiac surgeons and interven- tional cardiologist team (1). As a result of this complex operation, the right ventricle will pump blood to pulmonary and systemic circulation. The blood passes through arterial duct will, therefore, have a high pressure, with low oxygen partial pressure $\left(\mathrm{PO}_{2}\right)$. Reported disadvantages of hybrid approach include the need for antiplatelet aggregation prophylaxis, the potential risk of reverse coarctation and possibly other complications while waiting for stage II (Glenn shunt and aortic arch reconstruction) palliation (2).

During the fetal life, the arterial duct is kept open by three mechanism: 1) the elevated intravascular pressure within the arterial duct due to constricted pulmonary vascular bed and high pulmonary vascular resistance. 2) endogenous production of Prostaglandin- $E_{2}\left(P G-E_{2}\right)$ produced by the duct endothelium. 3) The increased intracellular concentration of CAMP, nitric oxide production by fetal arterial duct and increased carbon monoxide production by endothelial and smooth muscle cell of the duct play an important role to keep the duct patent (3). After delivery, several factors stimulate the duct constriction and closure, such as: increased $\mathrm{PO}_{2}$, reduced pressure within the duct lumen and decreased $\mathrm{PG}_{2}$ secretion and its receptors.

Surgical banding of pulmonary artery branches, as part of the hybrid approach, would limit blood flow through the pulmonary artery branches and direct

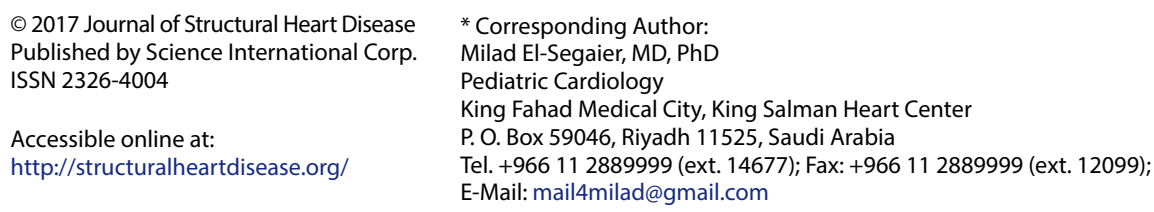

(c) 2017 Journal of Structural Heart Disease Published by Science International Corp. ISSN 2326-4004

Accessible online at: http://structuralheartdisease.org/

* Corresponding Author:

Milad El-Segaier, MD, PhD

Pediatric Cardiology

King Fahad Medical City, King Salman Heart Center

P. O. Box 59046, Riyadh 11525, Saudi Arabia

Tel. +966 112889999 (ext. 14677); Fax: +966 112889999 (ext. 12099);

E-Mail: mail4milad@gmail.com 
the blood flow toward the arterial duct. This resulted in maintaining high intraluminal pressure within the duct, and the blood flowing through it will have low arterial PO2. The availability of both factors leads to a situation mimicking intrauterine status. This makes us hypothesize that the arterial duct, even without stenting, may still remain patent following pulmonary artery branch banding. We understand that this hypothesis needs to be discussed and tested further. However, it is worth to be thought about, as it might simplify the hybrid procedure and eliminate stent-related complications. We would be interested to hear the thoughts of the respective readers.

\section{Conflict of Interest}

The authors have no conflict of interest relevant to this publication.

\section{Comment on this Article or Ask a Question}

\section{References}

1. Akintuerk $\mathrm{H}$, Michel-Behnke $\mathrm{I}$, Valeske $\mathrm{K}$ Mueller M, Thul J, Bauer J, Hagel KJ, et al. Stenting of the arterial duct and banding of the pulmonary arteries: basis for combined Norwood stage I and II repair in hypoplastic left heart. Circulation. 2002 Mar 5;105(9):1099-103. DOI: 10.1161/ hc0902.104709
2. Galantowicz M, Cheatham JP. Lessons learned from the development of a new hybrid strategy for the management of hypoplastic left heart syndrome. Pediatr Cardiol. 2005 May-Jun;26(3):190-9. DOI: 10.1007/s00246-004-0962-4

3. Clyman RI. Mechanisms regulating the ductus arteriosus. Biol Neonate. 2006;89(4):330-5. DOI: 10.1159/000092870
Cite this article as: El-Segaier M, Galal MO. Do We Need to Stent Arterial Duct in Hybrid Approach for Hypoplastic Left Heart Syndrome? Structural Heart Disease. 2017;3(5):163-164. DOI: http:// dx.doi.org/10.12945/j.jshd.2017.044.17 